\title{
The associations of comorbidities and consumption of fruit and vegetable with quality of life among stomach cancer survivors
}

Ji-Wei Wang ${ }^{1 \dagger}$, Cheng-Gang Zhang ${ }^{2 \dagger}$, Qing-Long Deng ${ }^{1}$, Wan-Li Chen ${ }^{1}$, Xian Wang ${ }^{2^{*}}$ and Jin-Ming Yu ${ }^{1 *}$

\begin{abstract}
Background: Stomach cancer survivors (SCS) often carry the dual burden of the cancer itself and other comorbidities; meanwhile, they are highly motivated to seek health advice about lifestyles to improve their health and quality of life (QOL). The associations of the comorbidity and the consumption of vegetable and fruit with QOL remain even less clear among the SCS. This study aimed to investigate the associations of comorbidities and consumption of fruit and vegetable with QOL among SCS.

Methods: A cross-sectional study was conducted among 969 SCS between April and July 2015 in Shanghai, People's Republic of China. Data were collected using a self-reported questionnaire, which included questions on sociodemographic characteristics, comorbidities and fruit and vegetable consumption, and a simplified Chinese version of the European Organization for Research and Treatment quality of life version 3 (EORTC QLQ-C30) questionnaire. In order to mitigate the bias caused by confounding factors, multiple linear regression models were employed to calculate the adjusted means of QOL scores.

Results: The proportion of participants without any comorbidity was only $23.3 \%$, and the most common comorbidity among SCS was digestive diseases (49.8\%). Participants with comorbidity generally reported lower scores for global health and functioning subscales and higher scores for symptom in EORTC QLQ-C30 compared to participants without comorbidity, indicating poorer QOL. Higher scores in most functioning subscales and lower scores in some symptoms subscales were found in participants (38.7\%) who ate more than $250 \mathrm{~g}$ vegetables every day, compared to participants with less vegetable consumption, and in participants (58.1\%) who ate fruit every day, compared to participants who didn't eat fruit every day indicating better QOL.

Conclusions: The comorbidities are common health problems among SCS and have significantly negative influence on QOL, and participants with comorbidities generally reported lower QOL scores. The enough vegetables and fruit consumption are positively associated with QOL of SCS. These findings suggested that a multidisciplinary team approach and a variety of delivery systems are needed to address the medical, psychosocial, and lifestyle components for enriching patient-centered care among SCS.
\end{abstract}

Keywords: Stomach cancer survivors, Quality of life, QLQ-C30, Comorbidity, Consumption of fruit and vegetable

\footnotetext{
* Correspondence: xianwangxh@126.com; jmy@fudan.edu.cn

${ }^{\dagger}$ Equal contributors

${ }^{2}$ Shanghai Xuhui Center for Disease Control and Prevention, 50

Young-Chuan Road, Shanghai 200237, China

${ }^{1}$ Key Lab of Health Technology Assessment of National Health Commission

and Key Lab of Public Health Safety of Ministry of Education, School of

Public Health, Fudan University, 130 Dong-An Road, Shanghai 200032, China
} 


\section{Background}

The stomach cancer incidence has been decreasing substantially in most parts of the world over the recent few decades [1-3]. However, there was still almost one million new cases of stomach cancer were estimated to have occurred in 2012, more than $70 \%$ of cases occurred in developing countries, and half of cases occured in Eastern Asia (mainly in China) [1]. Meanwhile, the number of stomach cancer survivors (SCS) in China may increase over time as a result of early detection and improved treatment [4].

Traditional indicators, such as survival and cure rate, cannot sufficiently reflect the effect of treatments and the health conditions of SCS. Quality of Life (QOL) is increasingly being used as a primary outcome measure in studies to evaluate the effectiveness of treatment, and long-term survival and functional status of cancer survivors, which means the individual's experience about the survival-related goals, expectations, standards and concerns in different cultures and value systems [5]. QOL is a multidimensional concept which covers various survival aspects related to physical, emotional, mental, sexual or social functioning [6]. World Health Organization emphasized the importance of the improvement of QOL in their global cancer control strategy [7].

Previous studies indicated that the QOL of SCS could be undermined by the side effects of cancer and its treatments, such as physiological effect of nausea or problems with swallowing [8], and a psychological effect of depression [9], and a social effect withdrawal due to embarrassment about being ill $[10,11]$. Assessment of QOL to monitor and care long-term SCS about medical and psychologic consequences of their cancer treatment and rehabilitation is imperative.

Cancer patients generally report more comorbidity than do patients without a history of cancer, with prevalence varying between cancer sites [12-14]. The number and severity of a survivor's comorbidities also affect clinical care, treatment options, health service needs, and prognosis of cancer $[15,16]$. There are a few studies which specifically investigated the association of comorbidity with the QOL of cancer survivors, and indicated that cancer survivors with certain comorbidities such as cardiovascular, respiratory, digestive, and musculoskeletal diseases had lower QOL $[17,18]$. However, the investigation of prevalence of comorbidity and the associations of comorbidities with QOL among SCS were still scarce.

Lifestyle factors, in terms of diet, have been shown to be important predictors of occurrence and recurrence cancer, as well as the QOL of cancer survivors. A high consumption of vegetables and fruit is strongly and consistently associated with a reduced stomach cancer risk [19-21]. Persons with a high intake of vegetables and fruit tended to have a 50\% reduction in stomach cancer risk, compared to the ones with a low intake [22]. In addition, Brown et al. observed that post-diagnosis diet quality was directly associated with subsequent mental and physical functioning in the breast cancer survivors, and this association was stronger for mental functioning than for physical functioning [23]. The breast cancer survivor with better nutritional status had better functioning scales (physical, role, cognitive, social) and QOL, and experienced fewer clinical symptoms [24]. However, few studies have assessed the impact of fruit and vegetable intake on QOL among SCS. It is important to provide more information to SCS to help them to learn the association of consumption of fruit and vegetable with QOL.

The specific objectives of this study are to investigate the prevalence of comorbidity and consumption of fruit and vegetable, and the associations of comorbidities and consumption of fruit and vegetable with QOL among SCS. A better comprehensive understanding of the influence of comorbidities and consumption of fruit and vegetable on QOL post-diagnosis is needed to improve model of care and maximizes QOL among SCS.

\section{Methods}

\section{Recruitments}

Between April and June in 2015, participants were recruited from seventeen multi-community cancer rehabilitation centers, all of which were affiliated Shanghai Cancer Rehabilitation Club (SCRC), Shanghai, China, a non-government organization serving cancer survivors exclusively. It covered all the 17 districts in Shanghai and has about 13,500 cancer survivor members in Shanghai by the end of 2014. This self-help support group aiming at improving survivors' quality of life regularly offers rehabilitation activities including physical exercise, relaxation training, nutritional and dietary counseling, psychotherapy and a variety of leisure aactivities [25]. The criteria for study enrollment are at least 16 years of age, stomach cancer as the first primary cancer, completed active treatment, able to independently participate in the activities of cancer rehabilitation club, and no cognitive impairment.

Total 1354 SCS have registered in the SCRC by the end of 2014 meet the above inclusion criteria. All members of the SCRC who intended to continue to participate in the SCRC were required to register annually, including both former and new members. The survey invitations were sent through short text messages or/and phone calls to all 1354 SCS. Among all these SCS, 131 were unable to reach because of deaths, migration or refusing to response; 254 failed to participate the survey either because they had no time, or because their health status or literacy ability was too poor. Finally, 969 (71. $57 \%$ ) participated this survey and formed our final 
sample, and completed the self-administered questionnaire, in his/her own home, or community activity center affiliated SCRC, which normally took 40-60 min.

\section{Instruments}

\section{Demographic characteristics}

The demographic characteristics included age, gender, body mass index, years since diagnosis, marital status, the highest educational level achieved, and monthly household income per capita.

\section{Comorbidities}

Participants were asked to indicate either "yes" or "no" on a list of comorbidities including hypertension, diabetes mellitus, heart diseases, stroke, respiratory diseases, digestive diseases, musculoskeletal diseases.

\section{Consumption of fruit and vegetable}

Vegetables intake was obtained using the choice question "How much vegetables do you eat?". The options were " $\leq 50 \mathrm{~g} /$ day", " $>50 \mathrm{~g} /$ day and $\leq 100 \mathrm{~g} /$ day", " $>100 \mathrm{~g} /$ day and $\leq 150 \mathrm{~g} /$ day", ">150g/day and $\leq 250 \mathrm{~g} /$ day", " $>250 \mathrm{~g} /$ day and $\leq 500 \mathrm{~g} /$ day" and "> $500 \mathrm{~g} /$ day". Fruit intake was obtained using choice question "Do you eat fruit?". The options were "No", "1 time/week", "2 times/ week", "3 times/week", "4-5 times/week", "Everyday".

\section{QOL measurements}

The QOL was measured by the European Organization for Research and Treatment quality of life version 3 questionnaire (EORTC QLQ-C30) simplified Chinese version [26]. The EORTC QLQ-C30 core questionnaire contains five functional scales (physical, role, cognitive, emotional, and social), three symptoms scales (fatigue, pain, and nausea and vomiting), a global health scale, a number of single items assessing additional symptoms commonly reported by cancer patients (dyspnea, appetite loss, insomnia, constipation, and diarrhea) and financial impact of the disease. For most items, four response categories from 1 (not at all) to 4 (very much) are employed; two items (overall health, overall quality of life) have response categories ranging from 1 to 7 . The scoring systems are organized such that a high scale score represents a higher response level. Thus a high score for a functional scale, the global health status or overall QOL represents a high or healthy status or a high QOL; however, a high score for the symptom scales represents a high level of symptomatology or problems. The scoring of the EORTC QLQ-C30 items was performed according to the EORTC scoring manual [27].

\section{Statistical analysis}

Standard statistical methods were used to examine potential differences in covariates by one-way analysis of variance (ANOVA) for continuous variables followed by Bonferroni post hoc tests. Comorbidity, vegetable intake, and fruit intake were conducted in the statistical analyses as dichotomous variables (yes/no, $\geq 250 \mathrm{~g} /$ day $/<$ $250 \mathrm{~g} /$ day, and everyday/not every day, respectively). Means and standard deviations were calculated for continuous variables, and numbers and percentages were computed for categorical variables. Multiple linear regression models were used to compute regression coefficients $(\beta)$ and associated 95\% confidence intervals as estimates of the mean difference of QOL scores associated with the presence or absence of comorbidities, adjusting for potential confounding variables. The following potentially confounding variables were included in all regression models: age (continuous), Body Mass Index (continuous), years since diagnosis (continuous), household income (continuous), education (junior high school or less, senior high school or vocational school, and junior college or above), and current marital status (married/living with partner or divorced/widowed/ separated/single). Linear regression was applied to each of the variables measured in EORTC QLQ-C30. Comorbidity and other diseases (hypertension, diabetes mellitus, etc.) were not included in one model. Statistical tests were based on a two-tailed probability with a significance level of 0.05. Statistical analyses were performed using the Statistical Package for the Social Sciences (SPSS) for Windows (Version 21.0).

\section{Results}

\section{The characteristics of the study sample}

The characteristics of the participants are shown in Table 1. Forty-four percent of the sample was 60 years old or above. Majority of them were married (89.2\%) and had at least one comorbidity (76.7\%). 15.1, 63.8 and $21.1 \%$ of the participants were underweight, normal weight and overweight or obese, respectively. In terms of the types of comorbidity, the proportion of SCS who suffered from digestive diseases (49.8\%) was the highest. Other comorbidities are listed according to their prevalence as follows: hypertension (30.4\%), diabetes mellitus (12.8\%), heart diseases (22.9\%), stroke (6.7), respiratory diseases (12.3\%), musculoskeletal diseases (29.6\%). 38.7\% of the participants ate more than $250 \mathrm{~g}$ vegetables every day, and $58.1 \%$ of participants who ate fruit every day.

\section{The association between comorbidities and adjusted scores of QOL}

The association between comorbidities and adjusted scores of QOL is presented in Table 2. The participants with self-reported CCD generally reported lower scores for most EORTC QLQ-C30 scales when compared to subjects without these CCD, indicating poorer QOL. The influences of diabetes, heart diseases, stroke, 
Table 1 Summary statistics of 969 stomach cancer survivors

\begin{tabular}{ll}
\hline variables & Number(\%) \\
\hline Sex & \\
$\quad$ Male & $515(53.1)$ \\
$\quad$ Female & $454(46.9)$ \\
Age(years): & \\
$\quad \leq 59$ & $309(31.9)$ \\
$60 \sim 69$ & $426(44.0)$ \\
$\geq 70$ & $234(24.1)$ \\
Body mass index (BMl, kg/m2) & \\
$<18.5$ & $146(15.1)$ \\
$18.5 \sim 24$ & $618(63.8)$ \\
$25 \sim 29$ & $198(20.4)$ \\
$\geq 30$ & $7(0.7)$ \\
Years since diagnosis & \\
$<2$ & $90(9.3)$ \\
$2 \sim 5$ & $229(23.6)$ \\
$>5$ & $650(67.1)$
\end{tabular}

Marital status

Married/with partner

Divorced/widowed/separated/single

Education

Junior high school or less

Senior high school or vocational school

Junior college or above

Monthly household income per capita (¥)

$<2000$

2000 4000

$>4000$

Number of comorbidities

0

1

2

$\geq 3$

Comorbidities

Hypertension

Diabetes

Cardiovascular

Stroke

Respiratory diseases

Digestive diseases

Musculoskeletal diseases

Vegetable intake

$<250 \mathrm{~g} /$ day

$\geq 250 \mathrm{~g} /$ day
Table 1 Summary statistics of 969 stomach cancer survivors (Continued)

\begin{tabular}{ll}
\hline variables & Number(\%) \\
\hline Fruit intake everyday & \\
Yes & $563(58.1)$ \\
No & $406(41.9)$ \\
\hline
\end{tabular}

respiratory diseases and musculoskeletal illnesses or digestive diseases on EORTC QLQC30 scores were of a similar magnitude and were larger than the influence of hypertension.

The association between consumption of fruit and vegetable and adjusted scores of $\mathrm{QOL}$

The association between consumption of fruit and vegetable and adjusted scores of QOL is presented in Table 3. The participants who ate more than $250 \mathrm{~g}$ vegetables every day, and participants who ate fruit every day, reported higher scores in most functioning subscales and lower scores in some symptoms subscales than participants who ate equal or less than $250 \mathrm{~g}$ vegetables every day, and participants who didn't eat fruit every day, respectively, indicating better QOL.

\section{Discussion}

This study examined the associations of comorbidities and consumption of fruit and vegetable with QOL among SCS. The SCS with comorbidities had a lower QOL score compared to the SCS without comorbidities, and the SCS with more consumption of fruit and vegetable had a higher QOL score.

In our study, comorbidity is common among SCS. Nearly $76.7 \%$ of subjects had at least one comorbidity, and more than half of them had two or more comorbidities. Noticeably, nearly $50 \%$ of the SCS had digestive diseases, which was the most common comorbid condition in our samples. The potential adverse consequences of comorbidities pose a major challenge for the care of cancer survivors, and comorbidity has been shown to be an important prognostic factor for patients with cancer [16]. Furthermore, our results showed that these comorbidities impacted the QOL of SCS. Therefore, to better address the health needs of SCS, a more comprehensive understanding of relationships between comorbidities, cancer and QOL is needed. However, sequential provision of services (primary care interrupted by oncology care on an episodic basis) does not offer optimal care either for comorbidity or for cancer in the contemporary China [28]. Comprehensive cancer care must provide ongoing monitoring and management for the comorbidity of cancer survivors, which may not only prolong the survival [29], but also improve the QOL of cancer survivor. 
Table 2 The association between comorbidities and adjusted scores of QOL among stomach cancer survivors

\begin{tabular}{|c|c|c|c|c|c|c|c|c|}
\hline & $\begin{array}{l}\text { With Comorbidity, } \\
\text { (without comorbidity) }\end{array}$ & $\begin{array}{l}\text { With HPT, } \\
\text { (without HPT) }\end{array}$ & $\begin{array}{l}\text { With DM, } \\
\text { (without DM) }\end{array}$ & $\begin{array}{l}\text { With HD, } \\
\text { (without HD) }\end{array}$ & $\begin{array}{l}\text { With STR } \\
\text { (without STR) }\end{array}$ & $\begin{array}{l}\text { With RD } \\
\text { (without RD) }\end{array}$ & $\begin{array}{l}\text { With DD } \\
\text { (without DD) }\end{array}$ & $\begin{array}{l}\text { With MD } \\
\text { (without MD) }\end{array}$ \\
\hline \multirow[t]{2}{*}{$\mathrm{PF}$} & $-3.52^{* * *}$ & $-1.72^{* * *}$ & $-2.79^{* * *}$ & $-4.85^{* * *}$ & $-6.87^{* * *}$ & $-5.77^{* * *}$ & $-2.54^{* * *}$ & $-4.73^{* * *}$ \\
\hline & (85.94) & (83.26) & (83.24) & $(83.86)$ & (83.01) & (83.48) & (83.66) & $(84.16)$ \\
\hline \multirow[t]{2}{*}{ RF } & $-2.67^{* * *}$ & $-1.15^{*}$ & $-3.13^{* * *}$ & $-4.30^{* * *}$ & $-6.42^{* * *}$ & $-5.90^{* * *}$ & $-1.63^{* * *}$ & $-4.38^{* * *}$ \\
\hline & (91.89) & (90.19) & $(90.36)$ & $(90.92)$ & (90.31) & $(91.02)$ & (91.48) & $(91.97)$ \\
\hline \multirow[t]{2}{*}{$\mathrm{EF}$} & $-3.75^{* * *}$ & $-1.43^{* * *}$ & $-3.00^{* * *}$ & $-4.98^{* * *}$ & $-5.84^{* * *}$ & $-4.93^{* * *}$ & $-3.28^{* * *}$ & $-5.31^{* * *}$ \\
\hline & $(85.81)$ & $(85.53)$ & $(85.82)$ & (86.49) & (85.61) & (85.78) & $(86.70)$ & $(87.01)$ \\
\hline \multirow[t]{2}{*}{$\mathrm{CF}$} & $-4.45^{* * *}$ & $-1.04^{*}$ & $-3.17^{* * *}$ & $-5.92^{* * *}$ & $-6.64^{* * *}$ & $-6.14^{* * *}$ & $-3.86^{* * *}$ & $-6.45^{* * *}$ \\
\hline & (83.18) & (79.37) & (79.24) & $(80.45)$ & (78.97) & (79.87) & (81.35) & $(81.46)$ \\
\hline \multirow[t]{2}{*}{ SF } & $-4.72^{* * *}$ & $-1.59^{* *}$ & $-2.70^{* * *}$ & $-6.26^{* * *}$ & $-8.21^{* * *}$ & $-8.80^{* * *}$ & $-4.29 * * *$ & $-5.76^{* * *}$ \\
\hline & $(81.51)$ & (77.33) & $(77.28)$ & $(78.60)$ & $(77.27)$ & $(77.87)$ & (79.33) & (79.00) \\
\hline \multirow[t]{2}{*}{ QL } & $-6.03^{* * *}$ & $-3.18^{* * *}$ & $-4.63^{* * *}$ & $-7.21^{* * *}$ & $-8.13^{* * *}$ & $-7.26^{* * *}$ & $-4.28^{* * *}$ & $-6.37^{* * *}$ \\
\hline & $(68.41)$ & $(64.04)$ & $(63.66)$ & $(64.87)$ & $(63.25)$ & $(64.03)$ & (64.98) & $(65.85)$ \\
\hline \multirow[t]{2}{*}{ FA } & $7.37^{* * *}$ & $1.89^{* * *}$ & $3.56^{* * *}$ & $6.85^{* * *}$ & $9.12^{* * *}$ & $7.55^{* * *}$ & $6.07^{* * *}$ & $7.38^{* * *}$ \\
\hline & $(23.48)$ & $(28.18)$ & (28.24) & (27.09) & (28.34) & $(27.80)$ & (25.39) & $(26.14)$ \\
\hline \multirow[t]{2}{*}{ NV } & 0.41 & 0.42 & $0.84^{*}$ & $2.26^{* * *}$ & $2.77^{* * *}$ & $3.29^{* * *}$ & $0.50^{*}$ & $1.60^{* * *}$ \\
\hline & $(4.72)$ & $(5.75)$ & $(5.56)$ & $(5.05)$ & $(5.29)$ & $(5.11)$ & $(4.80)$ & $(4.97)$ \\
\hline \multirow[t]{2}{*}{ PA } & $6.41^{* * *}$ & $2.09^{* * *}$ & $3.15^{* * *}$ & $6.66^{* * *}$ & $7.74^{* * *}$ & $7.12^{* * *}$ & $5.04^{* * *}$ & $12.00^{* * *}$ \\
\hline & $(10.96)$ & (16.09) & $(16.17)$ & (15.24) & $(16.41)$ & (15.79) & (13.40) & (12.79) \\
\hline \multirow[t]{2}{*}{ DY } & $5.53^{* * *}$ & $2.01^{* * *}$ & $2.87^{* * *}$ & $7.93^{* * *}$ & $8.18^{* * *}$ & $13.88^{* * *}$ & $3.83^{* * *}$ & $5.23^{* * *}$ \\
\hline & (12.48) & $(14.49)$ & $(14.97)$ & (13.18) & (14.95) & $(13.94)$ & (13.99) & $(13.93)$ \\
\hline \multirow[t]{2}{*}{$S L$} & $4.03^{* * *}$ & 0.70 & $2.17^{* * *}$ & $4.30^{* * *}$ & $5.43^{* * *}$ & $5.64^{* * *}$ & $3.18^{* * *}$ & $3.50^{* * *}$ \\
\hline & $(13.42)$ & $(18.22)$ & $(18.27)$ & (16.99) & (18.26) & $(17.74)$ & (15.83) & $(16.32)$ \\
\hline \multirow[t]{2}{*}{ AP } & $1.81^{* * *}$ & 0.74 & $2.02^{* * *}$ & $4.19^{* * *}$ & $5.00^{* * *}$ & $5.78^{* * *}$ & $2.07^{* * *}$ & $3.10^{* * *}$ \\
\hline & $(10.45)$ & $(12.15)$ & (12.68) & $(11.52)$ & $(12.45)$ & $(11.90)$ & $(10.85)$ & $(11.56)$ \\
\hline \multirow[t]{2}{*}{$\mathrm{CO}$} & $4.32^{* * *}$ & -0.17 & $2.62^{* * *}$ & $4.00^{* * *}$ & $4.61^{* * *}$ & $3.27^{* * *}$ & $4.19^{* * *}$ & $3.84^{* * *}$ \\
\hline & $(8.45)$ & (11.47) & (11.73) & $(11.22)$ & (11.34) & (11.39) & $(8.72)$ & $(10.14)$ \\
\hline \multirow[t]{2}{*}{$\mathrm{DI}$} & $2.68^{* * *}$ & $1.11^{* *}$ & $1.53^{* *}$ & $2.60^{* * *}$ & $2.66^{* * *}$ & $4.29^{* * *}$ & $3.12^{* * *}$ & $2.99^{* * *}$ \\
\hline & $(9.37)$ & $(11.75)$ & (11.49) & (10.82) & (11.53) & $(11.06)$ & $(8.86)$ & (10.09) \\
\hline \multirow[t]{2}{*}{$\mathrm{Fl}$} & $5.58^{* * *}$ & $1.81^{*}$ & $2.19^{*}$ & $6.47^{* * *}$ & $7.01^{* * *}$ & $8.68^{* * *}$ & $5.07^{* * *}$ & $6.33^{* * *}$ \\
\hline & $(27.96)$ & (32.01) & $(31.76)$ & $(30.40)$ & (31.45) & $(31.04)$ & (28.69) & $(29.67)$ \\
\hline
\end{tabular}

Abbreviations: $A P$ Appetite loss, $B M I$ Body mass index, CF Cognitive functioning, CO Constipation, $D D$ Digestive diseases, $D I$ Diarrhea, $D M$ Diabetes mellitus, $D Y$ Dyspnea; emotional functioning, EORTC QLQ-C30 European Organization for Research and Treatment quality of life version 3 questionnaire, FA Fatigue, FI financial difficulties, HD Heart diseases, HPT Hypertension, MD Musculoskeletal diseases, NV Nausea and vomiting, PA Pain, PF Physical functioning, QL Global health, QOL Quality of life, RD Respiratory diseases, RF Role functioning, SF Social functioning, SL Insomnia, SCS Stomach cancer survivors; stroke, STR Notes: ${ }^{*} P, 0.05,{ }^{* *} P, 0.01,{ }^{* * *} P, 0.001$

Multiple linear regression, adjusted for influence of sex, age, marital status, BMI, education, household income, time after diagnosis

Previous studies have demonstrated that healthy diet with enough vegetable and fruit intake was associated with better QOL of breast cancer survivors [23, 30]. Our research also reported similar findings that the SCS who ate more than $250 \mathrm{~g}$ of vegetables and some fruit every day were more likely to report higher overall QOL than those who did not engage in these healthy behaviors, indicating the benefits of consuming plenty of fruit and vegetable on QOL. Recent studies have suggested that increasing fruit and vegetable consumption can have beneficial effects on reducing recurrence or increasing survival for cancer survivors [31, 32]. Consistent with the 2010 Dietary Guidelines for Americans, cancer survivors should be encouraged to consume at least 2 to 3 cups of vegetables and 1.5 to 2 cups of fruits each day because of their health benefits [33]. Since it is difficult to identify which compounds of vegetables and fruits is beneficial the most, the reasonable advice is to consume plenty of various colorful vegetables and fruits daily.

Moreover, epidemiological studies have shown that high intakes of fruit and vegetables were associated with a lower risk of chronic diseases; particularly, cardiovascular 
Table 3 The association between consumption of fruit and vegetable and adjusted scores of QOL

\begin{tabular}{|c|c|c|}
\hline & Vegetable intake & Fruit intake everyday \\
\hline & $\geq 250 \mathrm{~g} /$ day $(<250 \mathrm{~g} /$ day $)$ & Yes (No) \\
\hline PF & $1.52^{* * *}(82.20)$ & $0.28(80.98)$ \\
\hline RF & $1.01 *(89.59)$ & $1.54^{* * *}(87.47)$ \\
\hline EF & $1.00^{* *}(84.54)$ & $1.12^{* *}(83.49)$ \\
\hline CF & $1.68^{* * *}(77.58)$ & $1.60^{* * *}(75.31)$ \\
\hline SF & $1.01 *(75.74)$ & $0.88(74.58)$ \\
\hline QL & $2.15^{* * *}(61.33)$ & $2.00^{* * *}(59.70)$ \\
\hline FA & $-1.17^{* *}(29.99)$ & $-1.01 *(31.58)$ \\
\hline NV & $-0.54^{*}(6.70)$ & $-0.27(6.60)$ \\
\hline PA & $-0.48(17.49)$ & $-1.10^{*}(18.44)$ \\
\hline DY & $-1.47^{* *}(16.26)$ & $-0.57(17.70)$ \\
\hline SL & $0.53(19.27)$ & $0.46(21.70)$ \\
\hline AP & $-1.52^{* * *}(14.43)$ & $-1.56^{* * *}(15.12)$ \\
\hline $\mathrm{CO}$ & $-1.12 *(13.24)$ & $-1.02 *(13.10)$ \\
\hline $\mathrm{Dl}$ & $-0.74^{*}(12.17)$ & $-0.33(12.28)$ \\
\hline $\mathrm{Fl}$ & $-0.85(32.01)$ & $-1.91^{* *(34.18)}$ \\
\hline
\end{tabular}

Abbreviations: AP Appetite loss, BMI Body mass index, CF Cognitive functioning, $C O$ Constipation, DI Diarrhea, DY Dyspnea; emotional functioning, EORTC QLQ-C30 European Organization for Research and Treatment quality of life version 3 questionnaire, FA Fatigue, FI Financial difficulties, NV Nausea and vomiting, PA Pain, PF Physical functioning, QL Global health, $Q O L$ Quality of life, RF Role functioning, SF Social functioning, SL Insomnia, SCS Stomach cancer survivors; stroke, STR

Notes: ${ }^{*} P, 0.05,{ }^{*} P, 0.01,{ }^{* * *} P, 0.001$

Multiple linear regression adjusted for influence of sex, age, marital status, $\mathrm{BMI}$, education, household income, time after diagnosis,number of comorbidities

disease [34, 35] and type 2 diabetes [36]. Consumption of vegetables and fruits impact not only cancer but also its commodities. Therefore, it is crucial to understand the importance of fruit and vegetable consumption, for comprehensive management program among SCS with comorbidities. However, changing behavioral risk factors and maintaining a healthy lifestyle were not easy for cancer survivors. Comprehensive chronic disease management models may be particularly appropriate in this regard, it should emphasize the continuity of long-term care, multidisciplinary cooperation, and specially, a relationship between patient and provider in which the patient was empowered and takes an active role in their ongoing care $[37,38]$, such as eating more vegetables and fruit.

The study has limitations that should be mentioned. First, all participants were the member of the SCRC, even though the SCRC recruited these members from community and hospitals using extensive recruitment channels. We acknowledge that selection bias may affect the study results. Second, information for only few clinical indicators was collected. Some important clinical indicators were not included, such as cancer stage, cancer metastatic and cancer recurrence, which could potentially confound the impact of comorbidity and consumption of fruit and vegetable on QOL. Examining the association between cancer clinical indicators and QOL will be the focus of our future study. Thirdly, the validity of self-reported comorbidity could be questionable [39], however, in our study we made it clear to the respondents that the comorbidity must be a clinical diagnosis. Given the crosssectional nature of the study, we cannot deduce causal relationships between comorbidity, consumption of fruit and vegetable, and QOL of SCS, but merely describe probable associations. Further and different studies are needed to explore these kinds of associations.

\section{Conclusion}

The comorbidities are common health problems among SCS and have significantly negative influence on QOL. High consumption of vegetables and fruit is positively associated with QOL of SCS. These findings warrant the comprehensive cares for SCS. A multidisciplinary team approach and a variety of delivery systems are needed to address the medical, psychosocial, and lifestyle components for enriching patient-centered care.

\section{Abbreviations}

EORTC QLQ-C30: European Organization for Research and Treatment quality of life version 3 questionnaire; QOL: Quality of life; SCS: Stomach cancer survivors

\section{Acknowledgements}

We would like to thank the Shanghai Cancer Rehabilitation Club for supporting this study. We are very grateful to all colorectal cancer survivors who willingly and generously gave their time.

\section{Funding}

None.

\section{Availability of data and materials}

The dataset supporting the conclusions of this article will not be available in a public repository because consent/approval was not obtained for the sharing of subject data from participants or the Medical Research Ethics Committee of the School of Public Health, Fudan University.

\section{Authors' contributions}

JW, JM and XW conceptualized and designed the study, analyzed and interpreted the data, and drafted the manuscript. CG, QL and WL analyzed and interpreted the data, and drafted the manuscript. All authors read and approved the final version of this manuscript.

\section{Ethics approval and consent to participate}

Ethical approval to conduct this study was granted by the Medical Research Ethics Committee of the School of Public Health, Fudan University (Protocol number RB \#2013-04-0450). A written informed consent was obtained from each participant.

\section{Consent for publication}

Not applicable.

\section{Competing interests}

The authors declare that they have no competing interest.

\section{Publisher's Note}

Springer Nature remains neutral with regard to jurisdictional claims in published maps and institutional affiliations. 
Received: 1 November 2017 Accepted: 27 March 2018

\section{Published online: 12 April 2018}

\section{References}

1. Zhu AL, Sonnenberg A. Is gastric cancer again rising? J Clin Gastroenterol. 2012:46:804.

2. Kamangar F, Dores GM, Anderson WF. Patterns of cancer incidence, mortality, and prevalence across five continents: defining priorities to reduce cancer disparities in different geographic regions of the world. J Clin Oncol. 2006;24:2137-50.

3. Bosetti C, Bertuccio P, Malvezzi M, Levi F, Chatenoud L, Negri E, et al. Cancer mortality in Europe, 2005-2009, and an overview of trends since 1980. Ann Oncol. 2013;24:2657-71.

4. Zheng $L$, Wu C, Xi P, Zhu M, Zhang L, Chen S, et al. The survival and the long-term trends of patients with gastric cancer in shanghai, China. BMC Cancer. 2014;14:300.

5. Orley J, Kuyken W. Quality of life assessment: international perspectives. Berlin: Springer-Verlag; 1994.

6. Victorson D, Cella D, Wagner L, Kramer L, Smith M-L. Measuring quality of life in cancer survivors. Handbook of cancer survivorship. New York: Springer; 2007.

7. WHO.. WHO Cancer Control Strategy [EB/OL] (2016).http://www.who.int/ cancer/media/strategy/en/.

8. Talley NJ, Phung N, Kalatnar JS. ABC of the upper gastrointestinal tract: indigestion: when is it functional? BMJ. 2001;323:1294-7.

9. Yu H, Wang Y, Ge X, Wu X, Mao X. Depression and survival in Chinese patients with gastric cancer: a prospective study. Asian Pac J Cancer Prev. 2012;13:391-4

10. Patru CL, Surlin V, Georgescu I, Patru E. Current issues in gastric cancer epidemiology. Rev Med Chir Soc Med Nat lasi. 2013;117:199-204.

11. Hinzey A, Gaudier-Diaz MM, Lustberg MB, DeVries AC. Breast cancer and social environment: getting by with a little help from our friends. Breast Cancer Res. 2016;18(1):54.

12. Land LH, Dalton SO, Jensen MB, Ewertz M. Impact of comorbidity on mortality: a cohort study of 62,591 Danish women diagnosed with early breast cancer, 1990-2008. Breast Cancer Res Treat. 2012;131(3):1013-20.

13. Grønberg BH, Sundstrøm S, Kaasa S, et al. Influence of comorbidity on survival, toxicity and health-related quality of life in patients with advanced non-small-cell lung cancer receiving platinum-doublet chemotherapy. Eur J Cancer. 2010;46(12):2225-34.

14. Ng HS, Roder D, Koczwara B, Vitry A. Comorbidity physical and mental health among cancer patients and survivors: An Australian populationbased study. Asia Pac J Clin Oncol. 2018;14(2):e181-e192.

15. Patterson RE, Flatt SW, Saquib N, et al. Medical comorbidities predict mortality in women with a history of early stage breast cancer. Breast Cancer Res Treat. 2010;122(3):859-65.

16. Jørgensen TL, Hallas J, Friis S, Herrstedt J. Comorbidity in elderly cancer patients in relation to overall and cancer-specific mortality. $\mathrm{Br} J$ Cancer. 2012;106(7):1353-60

17. Fu MR, Chen C, Haber J, Guth A, Axelrod D. Comorbidities and quality of life among breast Cancer sunvivors: a prospective study. J Pers Med. 2015;5(3):229-42.

18. Marventano S, Forjaz MJ, Grosso G, Mistretta A, Giorgianni G, Platania A, et al. Health related quality of life in colorectal cancer patients: state of the art. BMC Surg. 2013;13(Suppl 2):S15.

19. Steevens J, Schouten L, Goldbohm RA, van den Brandt PA. Vegetables and fruits consumption and risk of esophageal and gastric cancer subtypes in the Netherlands cohort study. Int J Cancer. 2011;129(11):2681-93.

20. Ang TL, Ming Fock K. Clinical epidemiology of gastric cancer. Singap Med J. 2014:55(12):621-8

21. Key TJ. Fruit and vegetables and cancer risk. Br J Cancer. 2011;104(1):6-11.

22. Steinmetz KA, Potter JD. Vegetables, fruit, and cancer prevention: a review. J Am Diet Assoc. 1996;96:1027-39.

23. Wayne SJ, Baumgartner K, Baumgartner RN, Bernstein L, Bowen DJ, BallardBarbash R. Diet quality is directly associated with quality of life in breast cancer survivors. Breast Cancer Res Treat. 2006;96(3):227-32.

24. Mohammadi S, Sulaiman S, Koon PB, Amani R, Hosseini SM. Association of nutritional status with quality of life in breast cancer survivors. Asian Pac J Cancer Prev. 2013;14(12):7749-55.

25. Shanghai Cancer Rehabilitation Club. A brief introduction to the Shanghai Cancer Rehabilitation Cancer Club. Available from: http://www.shcrc.cn/ webs/field_news.aspx?id=35. Accessed 26 Feb 2014.
26. Aaronson NK, Ahmedzai S, Bergman B, et al. The European Organization for Research and Treatment of Cancer QLQ-C30: a quality-of-life instrument for use in international clinical trials in oncology. J Natl Cancer Inst. 1993;85(5): $365-76$.

27. Bottomley A. The EORTC quality of life group. EORTC QLQ-C30 scoring manual. 3rd ed. Brussels: EORTC Publications; 2001.

28. Yang GH. The prevention and control on the chronic non-communicable diseases during health reform in China. Med Philos. 2010;31(1):13-6.

29. Søgaard M, Thomsen RW, Bossen KS, Sørensen HT, Nørgaard M. The impact of comorbidity on cancer survival: a review. Clin Epidemiol. 2013;5(Suppl 1): 3-29.

30. Mosher CE, Sloane R, Morey MC, et al. Associations between lifestyle factors and quality of life among older long-term breast, prostate, and colorectal cancer survivors. Cancer. 2009;115(17):4001-9.

31. Dieli-Conwright CM, Lee K, Kiwata JL. Reducing the risk of breast Cancer recurrence: an evaluation of the effects and mechanisms of diet and exercise. Curr Breast Cancer Rep. 2016;8(3):139-50.

32. Schwedhelm C, Boeing H, Hoffmann G, Aleksandrova K, Schwingshackl L. Effect of diet on mortality and cancer recurrence among cancer survivors: a systematic review and meta-analysis of cohort studies. Nutr Rev. 2016: 74(12):737-48

33. US Department of Agriculture and US Department of Health and Human Services. Dietary guidelines for Americans, 2010. 7th. Washington, DC: US Government Printing Office (2010).

34. Mirmiran P, Noori N, Zavareh MB, Azizi F. Fruit and vegetable consumption and risk factors for cardiovascular disease. Metabolism. 2009:58(4):460-8.

35. Hung HC, Joshipura K, Jiang R, Hu FB, Hunter D, Smith-Warner SA, et al. Fruit and vegetable intake and risk of major chronic disease. J Natl Cancer Inst. 2004;96(21):1577-84.

36. World Cancer Research Fund (WCRF) Panel. Food, nutrition, physical activity, and the prevention of Cancer: a global perspective. Washington, DC: World Cancer Research Fund; 2007.

37. Fisher EB, Brownson CA, O'Toole ML, Shetty G, Anwuri W, Glasgow RE. Ecological approaches to self-management: the case of diabetes. Am J Public Health. 2005:95:1523-35.

38. McCorkle R, Ercolano E, Lazenby M, et al. Self-management: enabling and empowering patients living with cancer as a chronic illness. CA Cancer J Clin. 2011;61:50-62.

39. Katz JN, Chang LC, Sangha O, Fossel AH, Bates DW. Can comorbidity be measured by questionnaire rather than medical record review? Med Care. 1996;34:73-84.

\section{Submit your next manuscript to BioMed Central and we will help you at every step:}

- We accept pre-submission inquiries

- Our selector tool helps you to find the most relevant journal

- We provide round the clock customer support

- Convenient online submission

- Thorough peer review

- Inclusion in PubMed and all major indexing services

- Maximum visibility for your research

Submit your manuscript at www.biomedcentral.com/submit
Biomed Central 